\title{
CARACTERIZAÇÃO DO ESPELEOCLIMA DA GRUTA DO MATEUS (BONITO- MS) E APLICAÇÕES NO MANEJO ESPELEOLÓGICO E NA GESTÃO DO ESPELEOTURISMO
}

\author{
LOBO, Heros Augusto Santos - heroslobo@ufscar.br \\ Dep. Geografia, Turismo e Humanidades - Univ. Federal de São Carlos - \\ LOURENÇÃO, Marcos Luís Faleiros \\ Hospital Universitário - Univ. Federal da Grande Dourados/MS
}

\begin{abstract}
RESUMO: As cavernas são ambientes confinados e com menor influência direta da luz solar, aspectos fundamentais que regem os padrões atmosféricos em seu interior, caracterizando os espeleoclimas. O Brasil possui vastas áreas cársticas, com diversas cavernas com uso atual e potencial para uso turístico. Neste contexto, realizou-se um estudo espeleoclimático na gruta do Mateus, em Bonito-MS, para verificar suas condições de uso turístico, em conjunto com outros estudos de seu Plano de Manejo Espeleológico. Foram estudadas a temperatura e umidade relativa do ar, além de visitas-piloto para identificar impactos antrópicos nas variáveis ambientais. Em síntese, a temperatura externa variou entre $7,9^{\circ} \mathrm{C}$ e $45,5^{\circ} \mathrm{C}$, e a umidade relativa do ar entre $9,7 \%$ e $99,9 \%$. No ambiente interno típico, a temperatura oscilou entre $21,6{ }^{\circ} \mathrm{C}$ e $24,2^{\circ} \mathrm{C}$, e a umidade relativa entre $54,4 \%$ e $99,9 \%$. A análise dos dados obtidos por meio de agrupamentos hierárquicos e coeficientes de correlação permitiu a identificação de duas zonas no interior da caverna, além do microclima externo. Estas foram classificadas dentro dos níveis baixo e médio de fragilidade do espeleoclima, considerando também o impacto comprovado de $0,2^{\circ} \mathrm{C}$ gerado por grupos de visitantes no interior da caverna. Assim, conclui-se que a gruta do Mateus é apta para o turismo sob a ótica do espeleoclima, considerando o baixo impacto produzido pelas visitas-piloto, o rápido retorno da temperatura ao seu estado estacionário após o impacto e a fluidez da visitação em função da gruta possuir dois acessos distintos.
\end{abstract}

Palavras-chave: Microclima; Espeleoclima; Ecoturismo; Conservação Ambiental. SPELEOCLIMATE CHARACTERIZATION OF GROTTO OF MATEUS (BONITO COUNTY, BRAZIL) AND APLICATIONS IN SPELEOLOGICAL AND TOURIST MANAGEMENT

ABSTRACT: Caves are confined environments with less influence of the direct sunlight. These essential aspects conducts internal atmospheric patterns characterizing the speleoclimate. Brazil has extensive areas of karst, with several show caves and others with great tourist potential. In this context, a study was done about the speleoclimate of grotto of Mateus, located in Bonito county, to observe its tourist potential along with other studies of its plan of speleological management. Temperature and humidity were studied as well as pilot-visits to identify anthropic impacts on the environment. In synthesis the external temperature fluctuated between $7,9{ }^{\circ} \mathrm{C}$ to $45,5{ }^{\circ} \mathrm{C}$ and the humidity between $9,7 \%$ to $99,9 \%$. In a typical internal environment, the temperature ranged between $21,6{ }^{\circ} \mathrm{C}$ to $24,2{ }^{\circ} \mathrm{C}$, and the humidity $54,4 \%$ to $99,9 \%$. The analyses of the data obtained by hierarchical clustering and correlation coefficients allowed an identification of two atmospheric zones inside of the cave as well as the external microclimate. These were classified within low and medium levels speleoclimate fragility, also considering the proven impact of $0,2{ }^{\circ} \mathrm{C}$ generated by groups of visitors inside of the cave. The conclusion is that the grotto of Mateus can fit the tourism under the speleoclimate analysis considering: a) the low level of impact produced during the tests; b) the fast return of the temperature to the steady state after the impact; and c) the easy visitors flow due the fact that the cave has two distinct access.

Keywords: Microclimate; Speleoclimate; Ecotourism; Environmental Conservation. 


\section{INTRODUÇÃO}

Os estudos do espeleoclima vêm sendo desenvolvidos em diversas cavernas do mundo, com objetivos como: o estudo da dinâmica da atmosfera subterrânea; as pesquisas de paleoambientes e de modelagem climática para fins de compreensão do aquecimento global atual; e para o manejo sustentável do espeleoturismo (LOBO, 2012). No Brasil, os estudos espeleoclimáticos são mais escassos, sendo produzidos em sua maioria em cavernas turísticas para fins de manejo. Estudos mais amplos e extensos foram realizados na gruta de Ubajara, Ceará (VERÍSSIMO et al., 2005), gruta do Lago Azul, Mato Grosso do Sul (BOGGIANI et al., 2007) e na caverna Santana, São Paulo (LOBO, 2011; LOBO et al., 2012), entre outros poucos exemplos. Raras são as exceções de estudos feitos em cavernas antes de sua abertura formal para a visitação, como é o caso das grutas Olhos d'Água, no Paraná (CARVALHO, 2001), Nossa Senhora Aparecida, no Mato Grosso do Sul (BOGGIANI et al., 2007) e o Buraco do Inferno da Lagoa do Cemitério, na Bahia (LOBO, 2013).

A atmosfera das cavernas é marcada por singularidades que a diferenciam dos demais sistemas atmosféricos naturais, em função de fatores como o confinamento espacial, a ausência de luz e a baixa incidência de energia solar direta (BUECHER, 1999; CIGNA, 2004). Apresenta também processos físicoquímicos de transferência e conservação de energia e massa semelhantes aos encontrados em sistemas atmosféricos da superfície terrestre, mas em intensidades atenuadas na maioria dos casos (LUETSCHER et al., 2008). A reposição energética ocorre a partir de fluxos gasosos e hídricos de troca com o ambiente externo, o qual recebe incidência direta da radiação solar, bem como sob influência geotermal (STOEVA; STOEV, 2005; LUETSCHER et al., 2008). Estas e outras características diferem as cavernas de outros ambientes de pequena circulação atmosférica, particularizando-as dentre os microclimas e caracterizando-as como espeleoclimas (LOBO, 2012).

A análise do espeleoclima é feita com base no monitoramento contínuo de seus parâmetros físicos e químicos. As principais variáveis consideradas nos estudos atmosféricos são a temperatura do ar, a temperatura das rochas, espeleotemas e/ou do solo, a temperatura da água, a umidade relativa e absoluta do ar, a pressão atmosférica, os fluxos de água e de ar, as taxas de concentração de $\mathrm{CO}_{2}$ e de radônio $\left({ }^{222} \mathrm{Rn}\right)$ e a condensação nas paredes, teto e espeleotemas. Diversos fatores interferem na variabilidade da dinâmica atmosférica destas variáveis, tais como o confinamento espacial, a estratificação vertical, a movimentação relativamente pequena de massa e energia, a menor disponibilidade ou ausência total de luz e a estabilidade relativa dos parâmetros físico-químicos, que por sua vez é proporcional ao confinamento espacial, à profundidade e distância do meio externo e ao número e posição dos acessos ao ambiente externo (BAILEY, 2005; BOURGES et al., 2006). No entanto, os estudos espeleoclimáticos raramente consideram todas as variáveis ora mencionadas. Estas são utilizadas em função das necessidades específicas de cada estudo, sendo mais usuais no Brasil os monitoramentos de temperatura e umidade relativa do ar e a obtenção de valores pontuais das concentrações de $\mathrm{CO}_{2}$, sobretudo em função da limitação tecnológica ainda existente no país para esta finalidade (LOBO, 2012). 
Neste contexto, realizou-se uma pesquisa descritiva e experimental de caracterização geral do espeleoclima da gruta do Mateus, localizada no município de Bonito-MS (Figura 1), antes de sua abertura formal para a visitação turística. Os objetivos da pesquisa foram: a) estabelecer uma primeira análise dos padrões de variabilidade higrotérmica da gruta do Mateus; e b) Identificar eventuais impactos da presença humana com base em experimentos controlados de visitação. A pesquisa se justificou pela necessidade e oportunidade de realização de estudos de monitoramento ambiental prévio à abertura de uma caverna para o uso turístico, bem como pelo fato da caverna estar inserida em um dos mais importantes destinos de turismo de natureza do Brasil, onde as cavernas ocupam lugar de destaque entre os atrativos turísticos.

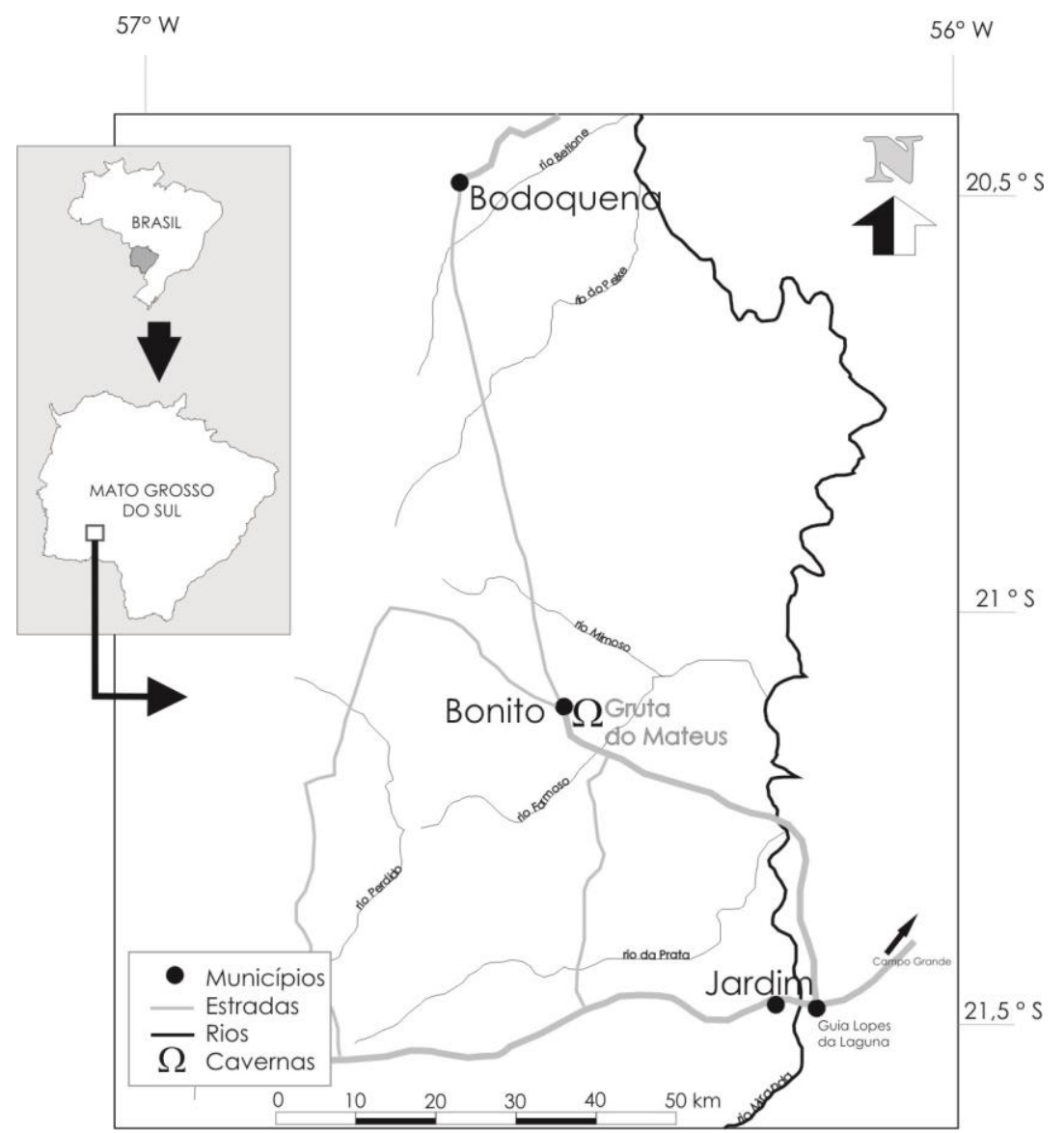

Figura 1.Localização da gruta do Mateus. Adaptado de Lobo e Moretti (2009).

\section{MATERIAIS E MÉTODOS \\ 2.1. Escopo e instrumentos}

Para a pesquisa de campo foram selecionadas duas variáveis fundamentais paraa compreensão da movimentação gasosa em ambientes cavernícolas: a temperatura e a umidade relativa do ar. A delimitação do estudo também considerou a necessidade de identificação das zonas higrotérmicas do ambiente. A conformação fisiográfica da gruta do Mateus - cavidade natural com dois acessos em altitudes distintas - suscitou a necessidade de uma compreensão da circulação gasosa, de forma a permitir a interpretação da estratificação da 
variabilidade espeleoclimática, o que no caso específico em questão, é fundamental para a interpretação do sistema atmosférico subterrâneo e da definição de critérios para o planejamento e gestão do turismo. Ao todo, a gruta possui $249 \mathrm{~m}$ de projeção horizontal (desenvolvimento linear: $375 \mathrm{~m}$ ), com galerias majoritariamente estreitas $(1 \sim 2 \mathrm{~m})$ e salões predominantemente baixos $(1,8 \sim 3 \mathrm{~m})$. Não existem cursos d'água ativos em seu interior.

Para a execução do monitoramento higrotérmico foram utilizados equipamentos da marca Testo, séries 175-H1 (série antiga e nova) e $177-\mathrm{H} 1$ e T2. A capacidade de memória dos instrumentos era variável entre 16 mil e 2 milhões de registros, e sua acurácia era de $0,2{ }^{\circ} \mathrm{C}$ para temperatura e $2 \%$ para umidade relativa do ar.Os instrumentos foram assim distribuídos: uma estação de monitoramento na área externa da cavidade, para correlação de dados, quatro estações na área interna, sendo três delas em trechos sujeitos à visitação e uma delas em área definida preliminarmente como sem interesse para a visitação (Figura 2). Esta distribuição considerou as necessidades: de identificar os padrões gerais de circulação atmosférica no ambiente; de verificar a existência de impactos antrópicos nas áreas visitadas e sua potencial dispersão para outras áreas da caverna; de obtenção de limites espaciais e temporais de uso da caverna de forma sustentável.

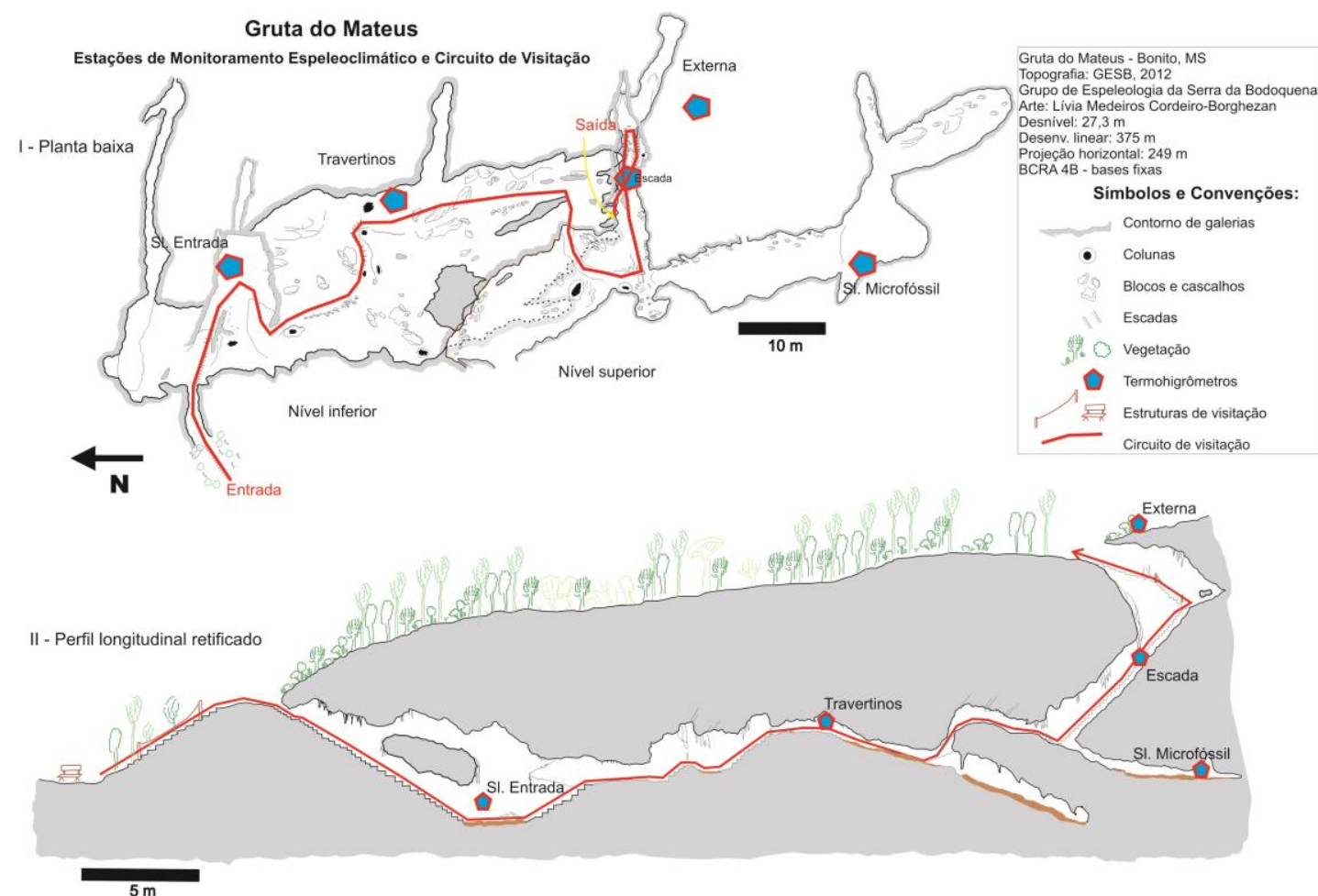

Figura 2. Localização em planta e perfildos pontos de monitoramento espeleoclimático na gruta do Mateus. Organizado pelos autores com base em GESB (2012).

O monitoramento teve início às 0:00h do dia 2 de junho de 2012, e término no dia 24 de novembro do mesmo ano, às 9:00h. Ao todo, foram registrados 8417 dados por variável em cada estação, em intervalos de 30 minutos. Um dos instrumentos (Salão Entrada) teve o funcionamento interrompido antes desta 
data, provavelmente por falha energética. Todavia, esta interrupção não interferiu nas análises realizadas.

\subsection{Análise e interpretação dos dados}

O primeiro conjunto de análises aplicado foi a estatística descritiva. Por meio dela, foram obtidas medidas de tendência central - média, moda e mediana - e de variabilidade - amplitude, desvio padrão e variância - para cada série de dados. Este procedimento permitiu a obtenção das simplificações necessárias para as análises estatísticas subsequentes.

Em um segundo momento, a análise dos dados foi aplicada visando à integração das variáveis analisadas entre as diversas estações de monitoramento, além dos dados originados por outros procedimentos de coleta. Para tanto, foram utilizados coeficientes de correlação $r$ de Pearson e análises de clusters, ou agrupamentos.A relação entre duas ou mais variáveis foi analisada por meio de gráficos, permitindo a interpretação da correlação visual entre os dados. Este procedimento foi utilizado, na maioria dos casos, em conjunto com os coeficientes de correlação $r$ de Pearson, que indica o grau de associação linear entre variáveis (GERARDI; SILVA, 1981), tal como utilizado em estudos espeleoclimáticos por Freitas; Schmekal (2006) e Lobo (2013), entre outros.

A análise de agrupamentos foi utilizada na discussão sobre zoneamento espeleoclimático, que partiu de conceitos já publicados por Stoeva e Stoev (2005), Lobo et al. (2009) e Lobo (2013). Tais experiências são ainda incipientes, sobretudo se comparadas a estudos mais gerais de climatologia, onde o zoneamento climático possui bases sólidas já construídas. Exemplos gerais que influenciaram a análise realizada foram encontrados em Cardoso e Dias (2004) para dados pluviométricos; Diniz et al. (2003) para zonas térmicas com base nas temperaturas máximas e mínimas; e Fritzsons et al. (2008) para a relação entre zonas climáticas e altitude. No presente estudo, os agrupamentos foram feitos por meio de dissimilaridades obtidas pela distância Euclidiana, com uso do método Ward, ambos sugeridos por Landim (2003) e testados com resultados satisfatórios por Lobo et al. (2009).

Os procedimentos estatísticos variados e multivariados foram executados por meio do pacote estatístico do $\mathrm{XLStat}^{\circledR}$, um aplicativo que funciona como suplemento do Excel ${ }^{\circledR}$ for Windows ${ }^{\circledR}$.

\subsection{Classificação dos níveis de fragilidade espeleoclimática da gruta do Mateus}

Considerando a finalidade do estudo realizado - a contribuição com o manejo espeleológico da gruta do Mateus -, o modelo espeleoclimático desenvolvido foi adaptado para a identificação das fragilidades da cavidade estudada, conforme metodologia proposta por Lobo et al. (2013). Para tanto, foi considerado como principal indicador a conectividade do espeleoclima com o meio externo, o qual foi analisado em conjunto com as respostas obtidas nas visitas-piloto realizadas na gruta durante o período de monitoramento. A classificação final se baseou nos níveis de fragilidade (baixo, médio, alto e absoluto) propostos por Lobo et al. 
(2013) e já aplicados no manejo espeleológico de cavernas do Estado de São Paulo (FUNDAÇÃO FLORESTAL; EKOS BRASIL, 2010).

\section{RESULTADOS}

Durante o período monitorado, a temperatura máxima do ambiente externo foi de $45,5^{\circ} \mathrm{C}$, valor este obtido às $15 \mathrm{~h}$ do dia 14 de setembro. Este valor pode ser considerado um extremo fora do padrão geral para a estação Externa, que apresentou outros picos acima dos $40^{\circ} \mathrm{C}$, mas cuja média no período foi de $24,17^{\circ} \mathrm{C}$. As mínimas registradas apresentaram diversos valores abaixo dos 10 ${ }^{\circ} \mathrm{C}$, com destaque para os $7,9^{\circ} \mathrm{C}$ às $5: 30 \mathrm{~h}$ do dia 7 de junho, sendo este o ápice do período mais frio registrado na série, entre os dias 4 e 8 do mês em questão. A umidade relativa do ar no ambiente externo atingiu a saturação $(99,9 \%)$ nos períodos noturnos, elevando a média geral da série na estação Externa para $68,48 \%$. Por outro lado, é notável o valor mínimo de $9,7 \%$ registrado no dia 5 de setembro, às 16:00h. Nas estações internas, o menor valor registrado para a umidade relativa do ar foi de $41,7 \%$ na estação Escada. Os gráficos das séries originais de temperatura e umidade relativa do ar são apresentados na Figura 3.

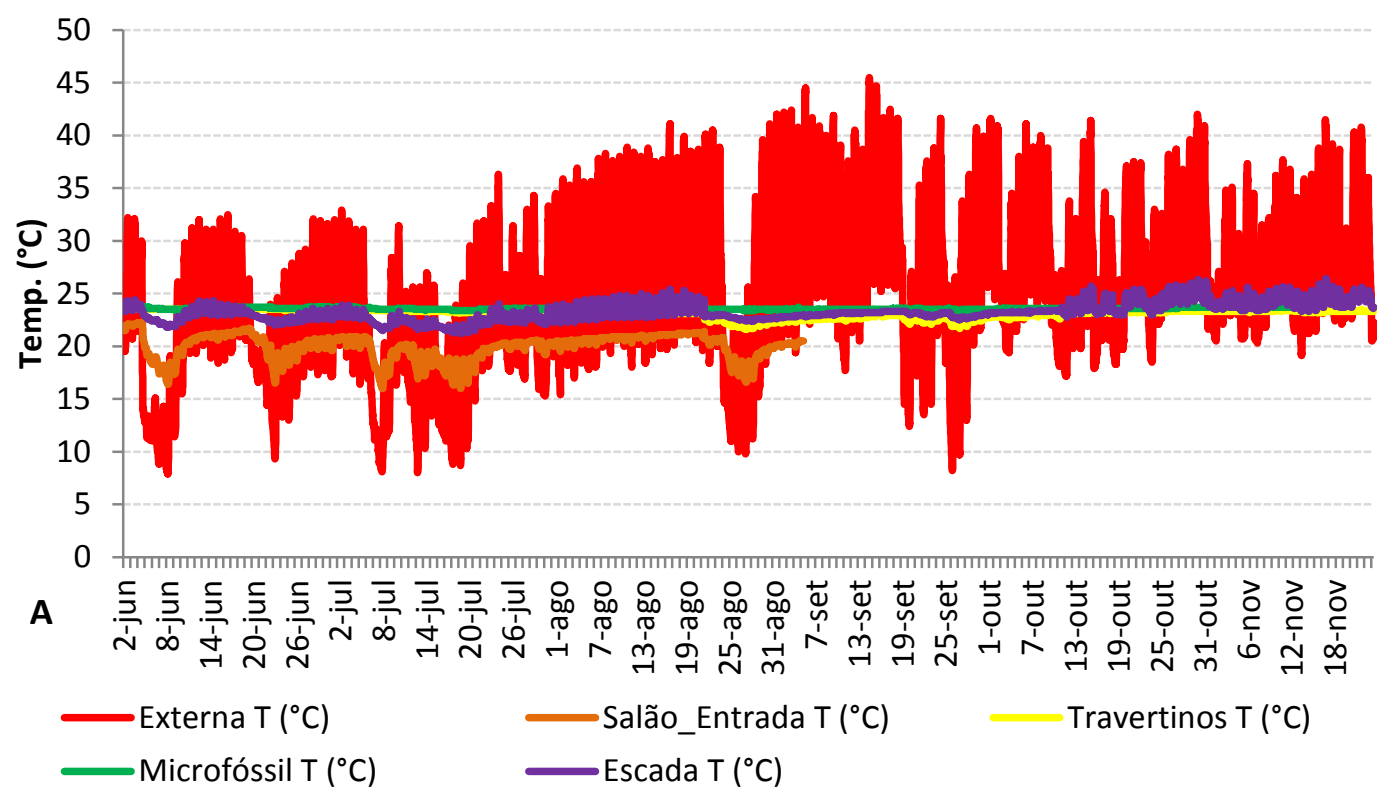




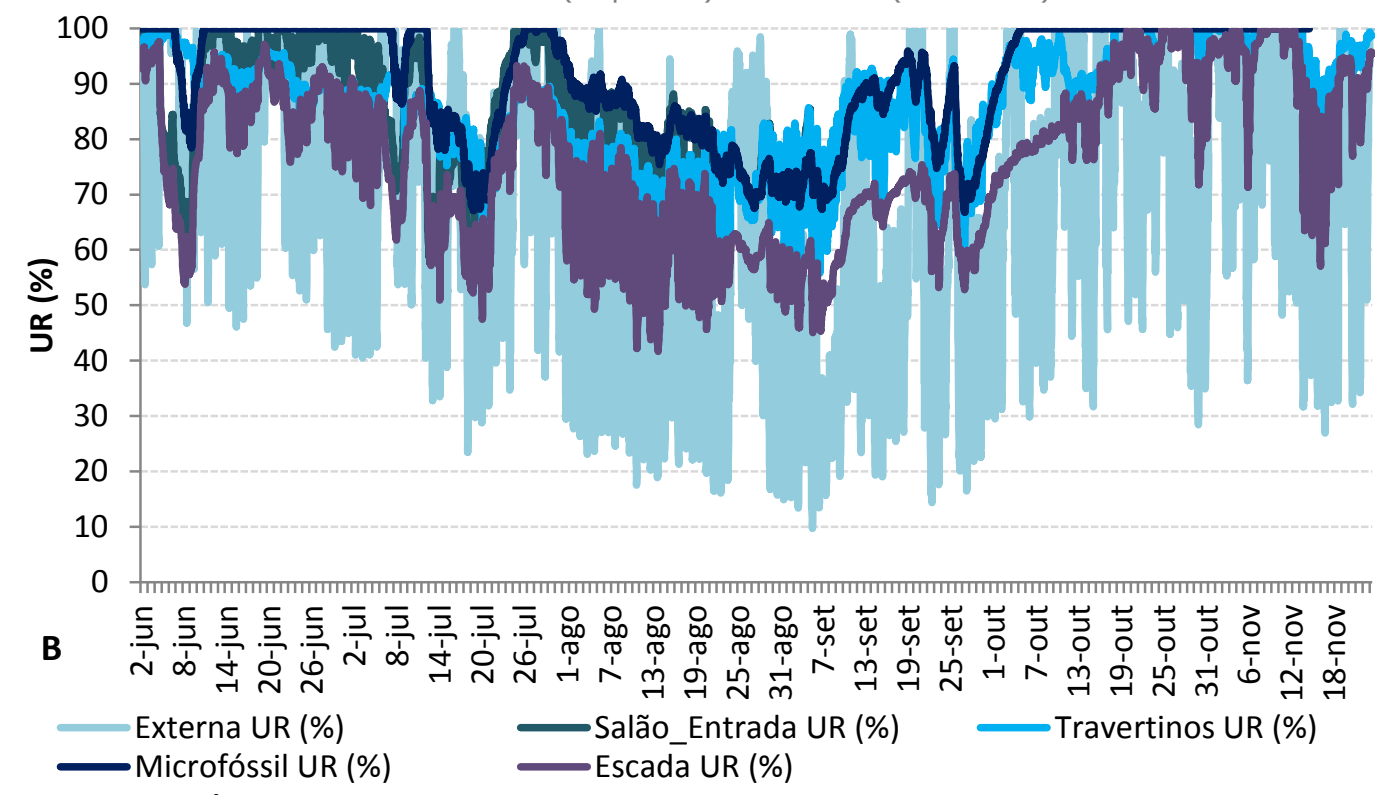

Figura 3. Séries completas de dados para a temperatura $(A)$ e umidade relativa do ar (B) da gruta do Mateus e área adjacente.

Pela Figura 3A, observa-se a correlação visual existente para a temperatura, entre a estação Externa e as estações Salão_Entrada e Escada, sendo estas as mais próximas dos acessos externos da cavidade. Aparentemente, a influência do clima externo é menor nas estações Travertinos e Microfóssil, as quais ficam em áreas com menor contato com o meio externo (Figura 2).

A estação Salão_Entrada apresentou variação de temperatura em níveis mais baixos que as demais estações da gruta, e mesmo que a estação externa. Esta variação foi atribuída à sua posição relativamente mais baixa que as demais estações, permitindo a configuração de uma pequena cold trap ${ }^{1}$ (cf. CIGNA, 2004) no local, a qual retém por mais tempo o ar frio, quer aquele capturado no ambiente externo, sobretudo à noite, quer aquele resfriado naturalmente pelo contato do ar com as rochas no interior da gruta. A variação da umidade relativa do ar do espeleoclima da gruta do Mateus se mostrou, em gráfico (Figura 3B), mais coesa com o ambiente externo. As acentuadas variações geradas no ciclo diuturno no meio externo são visualmente observáveis no comportamento da umidade relativa do ar nas estações internas, embora em menor amplitude. Estas interpretações preliminares são corroboradas pelos resultados da estatística descritiva das séries obtidas (Tabela 1).

\footnotetext{
${ }^{1}$ Armadilha para captura do ar frio, conforme tradução sugerida por Lobo (2012).
} 


\begin{tabular}{l|r|r|r|r|r}
\hline \multirow{2}{*}{$\begin{array}{c}\text { Temperatura do ar: } \\
\text { Medidas estatísticas }\end{array}$} & \multicolumn{5}{|c}{ Estações ( ${ }^{\circ} \mathbf{C}$ ) } \\
\cline { 2 - 6 } & Externa & Sl._Entrada & Travertinos & Microfóssil & Escada \\
\hline Máxima & 45,50 & 22,30 & 24,20 & 23,80 & 26,40 \\
\hline Média & 24,17 & 19,93 & 23,08 & 23,57 & 23,27 \\
\hline Moda & 21,4 & 20,70 & 23,30 & 23,50 & 23,20 \\
\hline Mínima & 7,90 & 16,00 & 21,60 & 23,40 & 21,20 \\
\hline Amplitude & 37,60 & 6,30 & 2,60 & 0,40 & 5,20 \\
\hline Desvio padrão & 7,09 & 1,26 & 0,40 & 0,09 & 0,90 \\
\hline Umidade relativa do ar: & & \multicolumn{5}{|c}{ Estações (\%) } & & \\
\cline { 2 - 6 } Medidas estatísticas & Externa & Sl._Entrada & Travertinos & Microfóssil & Escada \\
\hline Máxima & 99,9 & 99,9 & 99,9 & 99,9 & 99,9 \\
\hline Média & 68,48 & 85,13 & 85,85 & 90,94 & 76,55 \\
\hline Moda & 99,9 & 99,9 & 99,9 & 99,9 & 99,9 \\
\hline Mínima & 9,7 & 54,1 & 54,4 & 66,8 & 41,7 \\
\hline Amplitude & 90,2 & 45,8 & 45,5 & 33,1 & 58,2 \\
\hline Desvio padrão & 23,80 & 11,50 & 11,05 & 10,47 & 14,50 \\
\hline
\end{tabular}

Tabela 1. Estatística descritiva da umidade relativa do ar da gruta do Mateus e arredores.

Os dados da Tabela1evidenciam uma proximidade visual maior entre as estações Travertinos, Microfóssil e Escada, por meio de suas temperaturas médias (na casa dos $23^{\circ} \mathrm{C}$ ), máximas (Travertinos e Microfóssil na casa dos $24{ }^{\circ} \mathrm{C}$ ) e mínimas (Travertinos e Escada na casa dos $21^{\circ} \mathrm{C}$ ). Das amplitudes térmicas, destaque para a estação Microfóssil, onde a variação ocorreu entre os $23,4^{\circ} \mathrm{C}$ e $23,8{ }^{\circ} \mathrm{C}$, totalizando apenas $0,4{ }^{\circ} \mathrm{C}$. Observa-se a menor variação da temperatura do ar neste salão, caracterizando-o como um subsistema espeleoclimático com maior grau de isolamento em relação ao restante da caverna, corroborado pelo isolamento físico, estrangulamento espacial no acesso e posição relativa na caverna. A temperatura mínima mais elevada corrobora esta interpretação, pelo fato de ser maior que as estações em seu entorno imediato (Escada e Travertinos). Para a umidade relativa do ar, observa-se maior semelhança entre estações Salão_Entrada e Travertinos, tanto pelas médias (próx. 85\%) quanto pelas mínimas (próx. 54\%). No geral, os níveis de saturação hígrica do ar são elevados no interior da gruta, o que se observa por meio das mínimas (em sua maioria, acima dos 50\%), das médias (acima dos $75 \%)$ e das modas e máximas $(99,9 \%)$ em todas as estações internas.

\section{DISCUSSÃO DOS DADOS, ANÁLISE DE IMPACTOS ANTRÓPICOS E APLICAÇÕES NO MANEJO ESPELEOLÓGICO}

O monitoramento de temperatura e umidade relativa do ar demonstrou resultados condizentes com o esperado para os padrões espeleoclimáticos, como a variação atenuada destas variáveis em relação ao meio externo (ERASO, 1969; 
BAILEY, 2005) e a influência dos dois acessos no padrão de circulação atmosférica (ERASO, 1969; CIGNA, 2004). O padrão em relação ao ciclo diuturno também corresponde ao observado em estudos anteriores (e.g. BOURGES et al., 2006; ROCHA; GALVANI, 2011; LOBO, 2013), com uma variação inversa entra a temperatura e umidade relativa do ar na área externa (exemplo do mês de julho na Figura4A), direta dos mesmos parâmetros nas regiões interiores próximas aos acessos ao meio externo (Figura 4B) e variação da umidade relativa do ar com maior estabilidade na temperatura nas estações mais internas (Figura 4C).

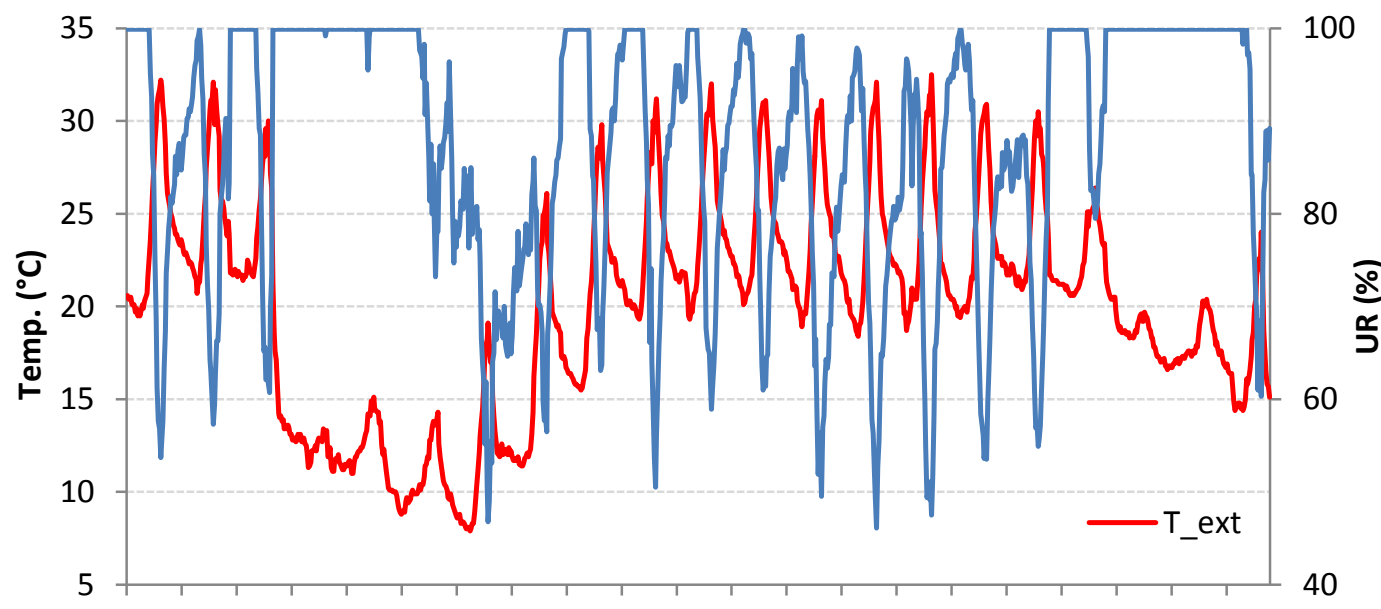

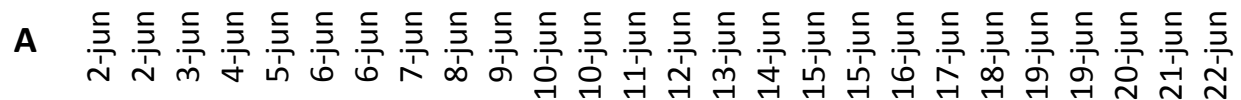

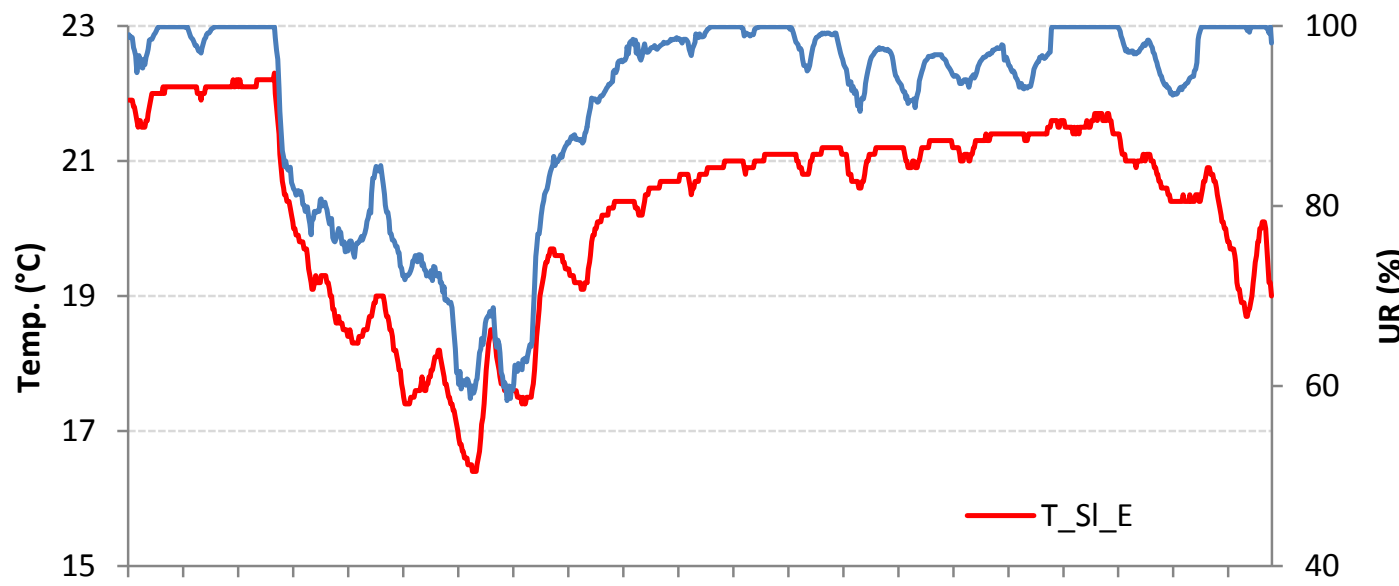

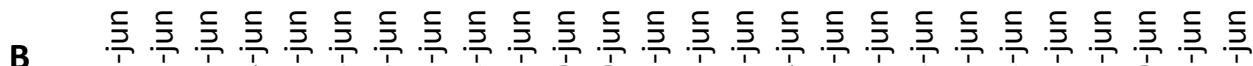

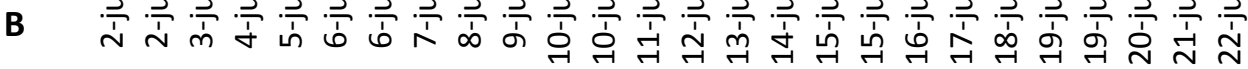




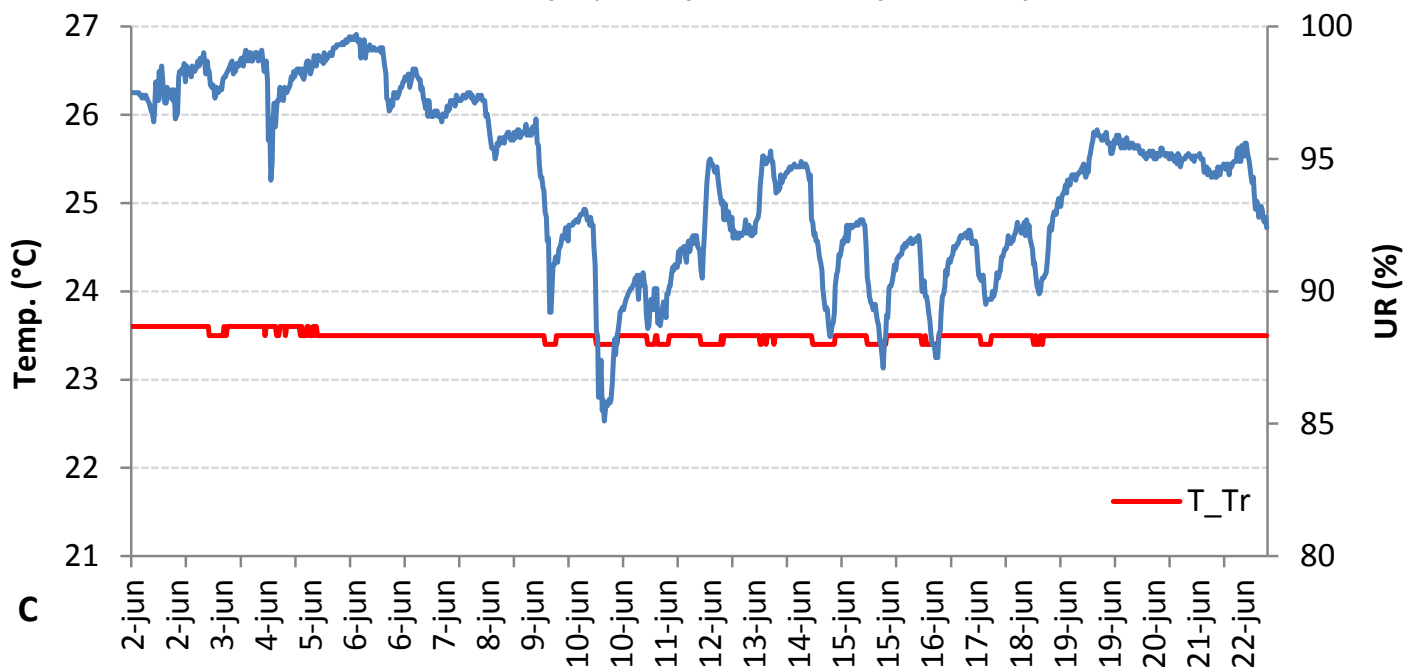

Figura 4: Variação da temperatura e umidade relativa do ar entre 2 e 22 de junho de 2012, nas estações Externa (A), Salão_Entrada (B) e Travertinos (C).

Estas observações são compatíveis com estudos anteriores realizados em cavernas com dois acessos, como os estudos espeleológicos para fins de manejo em cavernas no Estado de São Paulo (FUNDAÇÃO FLORESTAL; EKOS BRASIL, 2010), com exemplo representativo dos resultados publicado por Rocha; Galvani (2011) - que embora para caverna com um único acesso, também reforça as constatações do presente estudo.

A visualização destes distintos padrões de variação nas estações monitoradas enseja a primeira possibilidade de verificação das zonas espeleoclimáticas da cavidade (Figura 5).
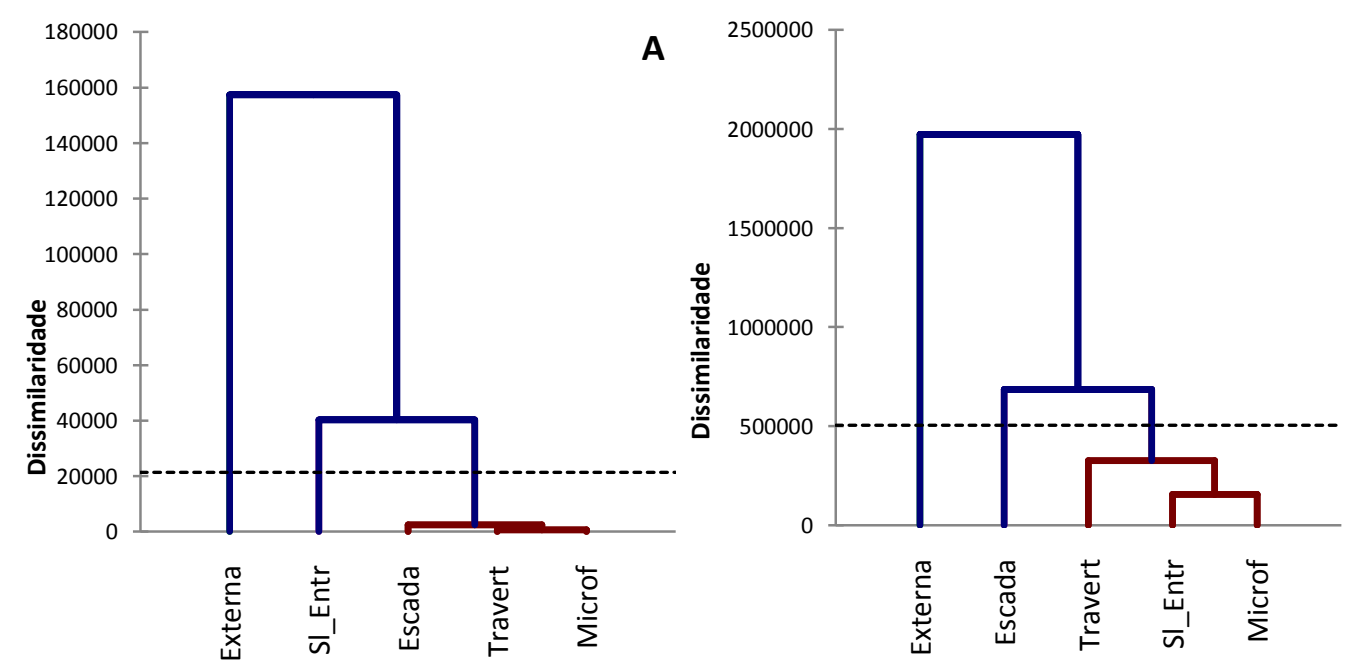

Figura 5. Dendrogramas resultantes da análise aglomerativa hierárquica para a Temperatura $(A)$ e umidade relativa do ar $(B)$ da gruta do Mateus. 
A análise da temperatura (Figura 5A) sugere que o espeleoclima da gruta do Mateus seja dividido em trêsgrupos distintos. Estes grupos são formados pelas seguintes estações:C1: Externa; C2: Salão_Entrada; C3: Escada, Travertinos, Microfóssil. Sob a ótica da temperatura, entende-se que o padrão diferenciado de circulação de ar do trecho da gruta próximo à estação Escada, caracterizado como uma cold trap (cf. CIGNA, 2004) secundária, certamente influenciou na caracterização dos agrupamentos obtidos. Na continuidade, sob a luz dos dados de umidade relativa do ar, também foram obtidos três agrupamentos (Figura 5B), compostos pelas estações:C1: Externa; C2: Travertinos, Salão_Entrada, Microfósseis; C3: Escada. Em trabalho de caracterização espeleoclimática da caverna Santana, Lobo et al. (2009) utilizou esta mesma técnica, mas sem considerar a Umidade relativa do ar para a obtenção dos agrupamentos. No caso da gruta do Mateus, este detalhamento não somente se faz possível, como se mostra bastante usual na verificação dos padrões ditados pela temperatura, expostos na Figura 5A. No caso da umidade relativa do ar, houve um resultado idênticopara o agrupamento da estação Externa. Todavia, para as estações internas, embora tenham sido identificados dois agrupamentos, estes diferem quanto às estações que os compõem. A estação Salão_Entrada, que estava isolada em um agrupamento pela temperatura, passou a ser integrada às estações Travertinos e Microfósseis sob a análise hígrica. A estação Escada, que pela temperatura se agrupava às estações Travertinos e Microfósseis, foi isolada em um agrupamento pela análise da Umidade Relativa. Todavia, Travertinos e Microfósseis permaneceram juntos em ambos os casos. Na tentativa de elucidar este impasse entre as estações próximas aos acessos, utilizou-se também o coeficiente de correlação $r$ de Pearson (Tabs.2 e 3).

\begin{tabular}{|c|c|c|c|c|c|}
\hline & Externa & SI_Entr. & Travert. & Microf. & Escada \\
\hline Externa & 1 & 0,655 & $-0,138$ & 0,020 & 0,723 \\
\hline & SI_Entr. & 1 & 0,177 & 0,449 & 0,772 \\
\hline & & Travert. & 1 & 0,524 & $-0,002$ \\
\hline & & & Microf. & 1 & 0,248 \\
\hline & & & & Escada & 1 \\
\hline
\end{tabular}

Tabela 3. Coeficientes de correlação ( $R$ dePearson) entre as séries de Umidade relativa do ar.

\begin{tabular}{|c|c|c|c|c|c|}
\hline & Externa & SI_Entr. & Travert. & Microf. & Escada \\
\hline Externa & 1 & 0,318 & 0,732 & 0,563 & 0,662 \\
\hline & SI_Entr. & 1 & 0,456 & 0,798 & 0,788 \\
\hline & & Travert. & 1 & 0,756 & 0,772 \\
\hline & & & Microf. & $\mathbf{1}$ & 0,854 \\
\hline & & & & Escada & 1 \\
\hline
\end{tabular}

Tabela 2. Coeficientes de correlação ( $r$ dePearson) entre as séries de Temperatura do ar.

Inicialmente, observa-se que a estação Salão_Entrada também possui coeficiente de correlação elevado $(0,772)$ com a estação Escada, sendo até maior do que com a estação Externa (Tabela 2).Quanto à Umidade relativa do ar 
(Tabela 3), a estação Salão_Entrada possui correlação alta e positiva com as estações Microfósseis $(0,798)$ e Escada $(0,788)$. A estação Escada também possui elevada correlação com a estação Microfósseis $(0,854)$. Estes dados permitem a formulação de uma interpretação geral do padrão espeleoclimático da gruta do Mateus. A variação de temperatura é sempre atenuada pela proteção física conferida pela gruta, de forma que as variações no ambiente externo se prolongam até a região dos acessos da caverna, ora representados pelas estações Salão_Entrada e Escada, com coeficientes $r$ de 0,655 e 0,723, respectivamente. Esta correlação é menor na estação Salão_Entrada, em função de sua configuração física e posição relativa mais baixa - propícia para o acúmulo de ar mais frio e denso (cf. ERASO, 1969) -, ocasionando a captura do ar mais frio, divergindo um pouco do padrão de variação diuturna externa no que diz respeito às temperaturas mais elevadas. Nas estações mais ao interior da gruta, não se observa influência significativa da Temperatura externa, como no caso da estação Travertinos $(r=-0,138)$ e Microfóssil $(r=0,020)$.

Por outro lado, os teores de Umidade relativa do ar no interior da caverna são mais afetados pelo meio externo. Isto se confirma pelos coeficientes de correlação entre a estação Externa e as estações Travertinos $(r=0,732)$, Escada $(r=0,662)$, Microfóssil $(r=0,563)$ e Salão_Entrada $(r=0,318)$, respectivamente. Esta situação foi interpretada como sendo fruto da termocirculação em tubo de vento (cf. ERASO, 1969), que possui diferentes padrões conforme as estações do ano. Embora não tenham sido feitos estudos de velocidade e direção de vento, levanta-se a hipótese de que a movimentação de massa de ar no período monitorado (inverno) ocorra da saída (acesso mais alto) para a entrada (acesso mais baixo). Teoricamente, conforme Eraso (1969), nos períodos quentes este fluxo se inverte - todavia, cabe lembrar que o monitoramento não foi realizado até o período do verão.

Por outro lado, a gruta do Mateus possui uma série de barreiras internas, com condutos parcialmente obstruídos, o que limita em parte esta circulação de ar. Entende-se que este fator é decisivo para que as variações de Temperatura se limitem às zonas de acesso da gruta. Em áreas mais distantes dos acessos ao meio externo, a temperatura varia bem menos, como modelado teoricamente e verificado na prática em estudos anteriores (CIGNA, 2004; FREITAS; SCHMEKAL, 2006). Um indício para este padrão também foi observado na gruta do Mateus, tomando como exemplo a amplitude térmica do salão Microfóssil, de apenas 0,4 ${ }^{\circ} \mathrm{C}$ no período monitorado.

Ainda, sobre a Umidade relativa do ar, a ausência de um corpo d'água ativo no interior da gruta do Mateus é fator decisivo para o seu comportamento, que não se encontra em saturação quase que constante, tal como observado em outras cavernas na região tropical sob o domínio da Mata Atlântica(e.g. VERÍSSIMO et al., 2005; LOBO, 2011; ROCHA; GALVANI 2011).As barreiras físicas que atenuam a velocidade do ar, permitindo seu resfriamento ao penetrar na gruta, não impedem que a água dissolvida no ar seja carreada para o seu interior. Desta forma, observa-se variação significativa neste parâmetro na maior parte do trecho monitorado, com exceção para o isolado salão Microfóssil.

Assim, com base nestes fatores e observações, a gruta do Mateus foi classificada em duas zonas espeleoclimáticas, com acréscimo da zona de microclima externo, representadas na Figura 6. 


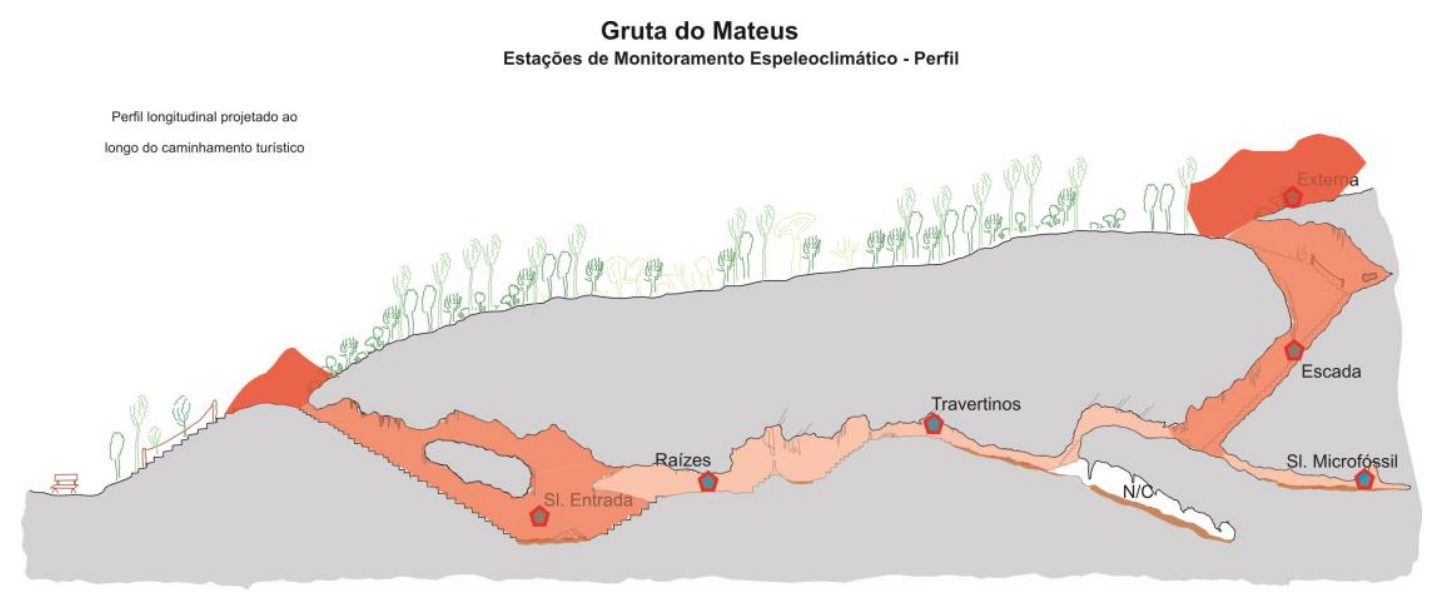

Figura 6. Zonas transicionais espeleoclimáticas (tons de vermelho), divididas em função dos salões da gruta do Mateus, e sua relação com o microclima externo.

Como ilustrado na Figura6, as zonas externas próximas aos acessos à caverna foram assumidas como sendo parte de um mesmo microclima, caracterizado por matas de galeria nas proximidades de cavidades naturais com moderada exposição direta ao sol, a qual é atenuada pelas árvores. Nesta zona, foram observados os maiores extremos de Temperatura $\left(7,9{ }^{\circ} \mathrm{C}-45,5{ }^{\circ} \mathrm{C}\right)$ e de Umidade Relativa $(9,7 \%$ - 99,9\%) de todos os pontos monitorados. Os trechos das escadas de acesso (que leva ao salão de Entrada) e de saída (local da estação Escada) foram classificados como uma zona transicional (cf. LOBO, 2013), marcada pela variação mais atenuada da Temperatura $\left(16,0{ }^{\circ} \mathrm{C}-26,4\right.$ $\left.{ }^{\circ} \mathrm{C}\right)$ e da Umidade Relativa do ar (45,8\% - 99,9\%). As demais estações foram classificadas como sendo integrantes da zona interna (cf. LOBO, 2013), com variações menores de Temperatura $\left(21,6{ }^{\circ} \mathrm{C}-24,2{ }^{\circ} \mathrm{C}\right)$ e relativamente menores de Umidade relativa do ar (54,4\% - 99,9\%). Uma área da gruta, correspondente à parte baixa de um de seus salões, mas que por ser parcialmente obstruído se configura como outro salão, não foi classificada (N/C), dado que os estudos desenvolvidos não permitem a extrapolação dos dados para este trecho.

Partindo das zonas climáticas, buscou-se obter a classificação da fragilidade espeleoclimática da gruta do Mateus. Para tanto, além dos resultados absolutos do monitoramento espeleoclimático, foram também consideradas as visitaspiloto executadas na caverna durante a pesquisa (Tabela 4). 
Revista Brasileira de Climatologia

ISSN: 1980-055x (Impressa) 2237-8642 (Eletrônica)

\begin{tabular}{r|r|r|r|r}
\hline Data & Entrada (h) & Saída (h) & Tempo total (min.) & Pessoas \\
\hline 09/jun & $15: 00$ & $15: 30$ & $00: 30$ & 7 \\
\hline $10 /$ jun & $16: 00$ & $16: 30$ & $00: 30$ & 2 \\
\hline $12 /$ jun & $16: 50$ & $17: 00$ & $00: 10$ & 2 \\
\hline $13 /$ jun & $16: 30$ & $16: 50$ & $00: 20$ & 1 \\
\hline $14 /$ jun & $16: 00$ & $16: 30$ & $00: 30$ & 1 \\
\hline $17 /$ jun & $17: 00$ & $17: 10$ & $00: 10$ & 2 \\
\hline $10 /$ nov & $09: 00$ & $09: 30$ & $00: 30$ & 2 \\
\hline $10 /$ nov & $09: 30$ & $10: 00$ & $00: 30$ & 2 \\
\hline $10 /$ nov & $16: 00$ & $16: 30$ & $00: 30$ & 1 \\
\hline $15 /$ nov & $16: 00$ & $16: 30$ & $00: 30$ & 2 \\
\hline $15 /$ nov & $16: 30$ & $17: 00$ & $00: 30$ & 2 \\
\hline $17 /$ nov & $10: 20$ & $11: 05$ & $00: 45$ & 13 \\
\hline $19 /$ nov & $15: 00$ & $15: 20$ & $00: 20$ & 13 \\
\hline $20 /$ nov & $15: 00$ & $15: 20$ & $00: 20$ & 7 \\
\hline $21 /$ nov & $16: 00$ & $16: 30$ & $00: 30$ & 13 \\
\hline $22 /$ nov & $15: 15$ & $16: 50$ & $01: 35$ & 23 \\
\hline & & & &
\end{tabular}

Tabela 4. Resultados das visitas-piloto realizadas na gruta do Mateus Fonte: Lourenção et al. (2013).

Dos dados apresentados, a análise se concentrou naqueles que se configuraram como grupos maiores, tomando por base o mínimo de sete pessoas. Assim, a análise foi feita com base nos dias 09/jun., 17, 19, 20, 21 e 22/nov. Considerando que a Temperatura do ar é o parâmetro que oferece a possibilidade de verificar os impactos da visitação (CIGNA, 2004; LOBO, 2012), foi feito um cruzamento destes dados selecionados com os valores de Temperatura do ar uma hora antes e até uma hora depois do término da visitação em cada estação de monitoramento (Figura 7).
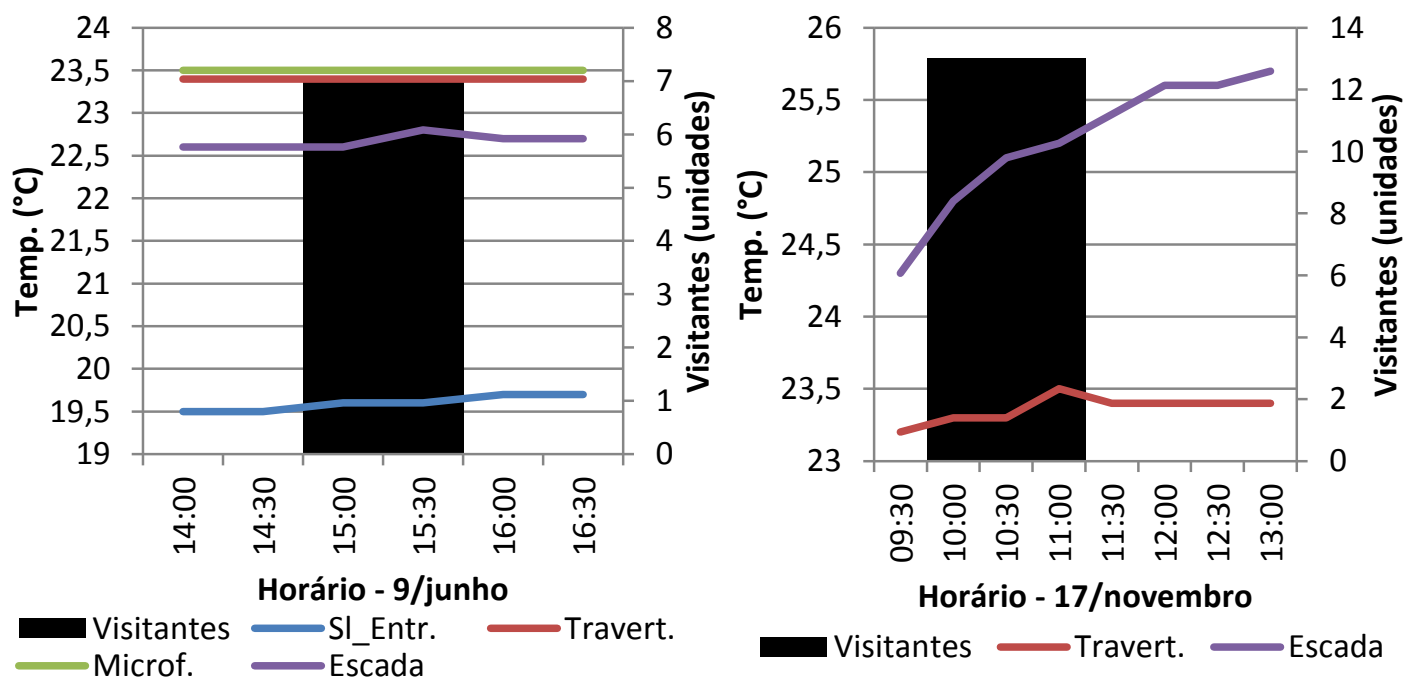


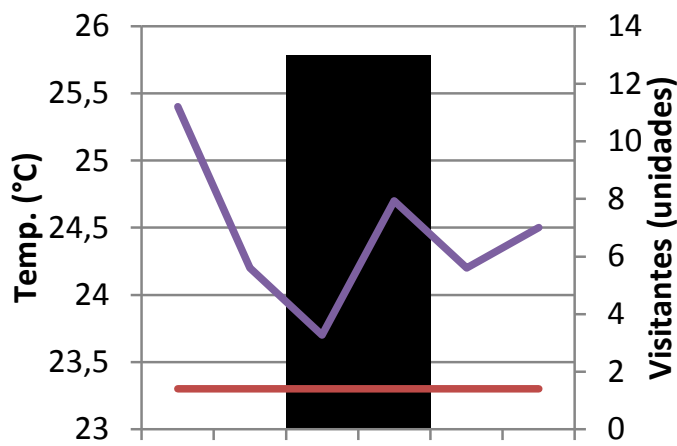

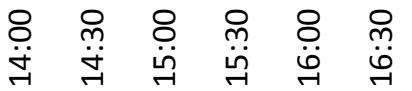

Horário - 19/Novembro

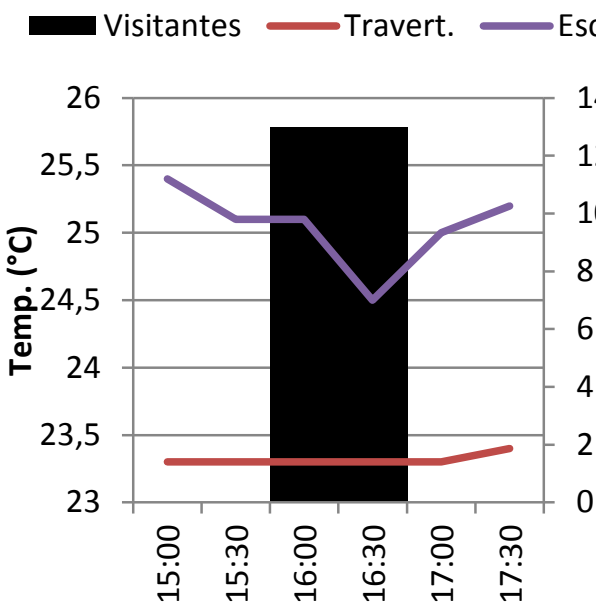

Horário - 21/Novembro

Visitantes Travert. Escada

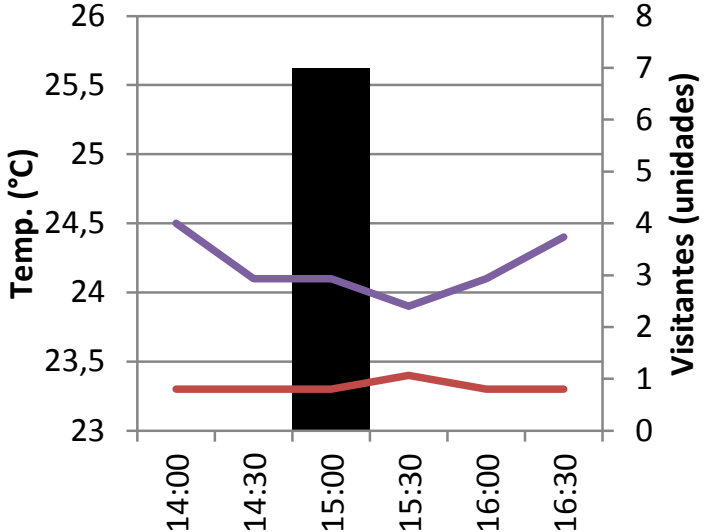

Horário - 20/Novembro
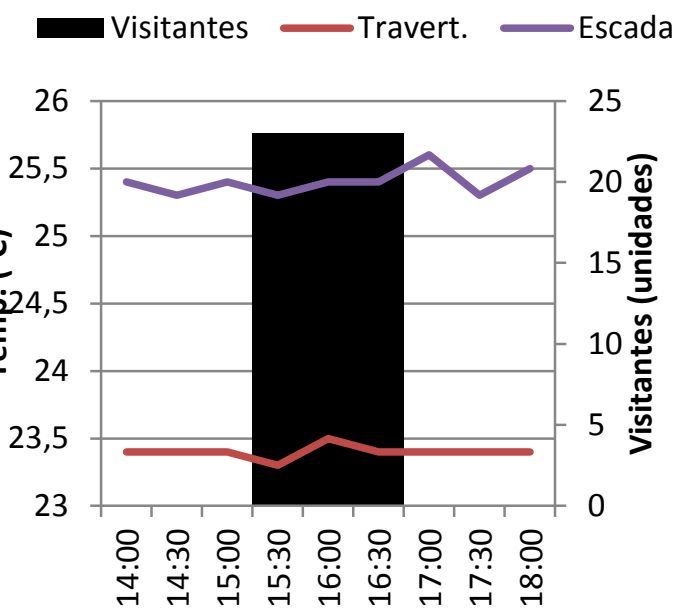

Horário - 22/Novembro

Visitantes Travert. $=$ Escada

Figura 7.Gráficos dos impactos da visitação no microclima nos dias 9 de junho, 17, 19, 20, 21 e 22 de novembro de 2012.

Com base na análise dos gráficos daFigura 7, foram identificados alguns impactos no espeleoclima que podem ser atribuídos à passagem de visitantes:

- $\quad$ 0,2 ${ }^{\circ} \mathrm{C}$ na estação Escada, no dia 9 de junho

- $\quad 0,2^{\circ} \mathrm{C}$ na estação Travertinos, no dia 17 de novembro

- $1,0^{\circ} \mathrm{C}$ na estação Escada, no dia 19 de novembro

- $\quad 0,2^{\circ} \mathrm{C}$ na estação Travertinos, no dia 22 de novembro.

Destes, o impacto na estação Escada, no dia 19 de novembro, foi o que apresentou maior magnitude, atingindo $1,0^{\circ} \mathrm{C}$. No entanto, é preciso considerar que neste dia, antes da visitação, a temperatura do ar estava na casa dos $25^{\circ} \mathrm{C}$. Assim, é possível que parte deste valor, se não sua totalidade, seja atribuído a uma variação natural da temperatura do ar, considerando que esta estação é mais sujeita as influências do microclima externo. Nos demais casos a variação registrada foi de $0,2^{\circ} \mathrm{C}$. 
Outro fator importante é o tempo de estabilização da temperatura, para verificar a intensidade do impacto e o retorno ao estado estacionário do parâmetro atmosférico analisado (LOBO et al., 2012). No caso da gruta do Mateus, todos os registros apontaram para um intervalo inferior a 30 minutos para a estabilização da temperatura, evidenciando a elevada dinâmica atmosféricado ambiente (cf. HEATON, 1986; LOBO, 2011) e também a baixa intensidade do impacto gerado. Partindo destes resultados e com base na classificação e parâmetros propostos por Lobo et al. (2013), desenvolveu-se o mapa de fragilidade espeleoclimática da gruta do Mateus (Figura 8).

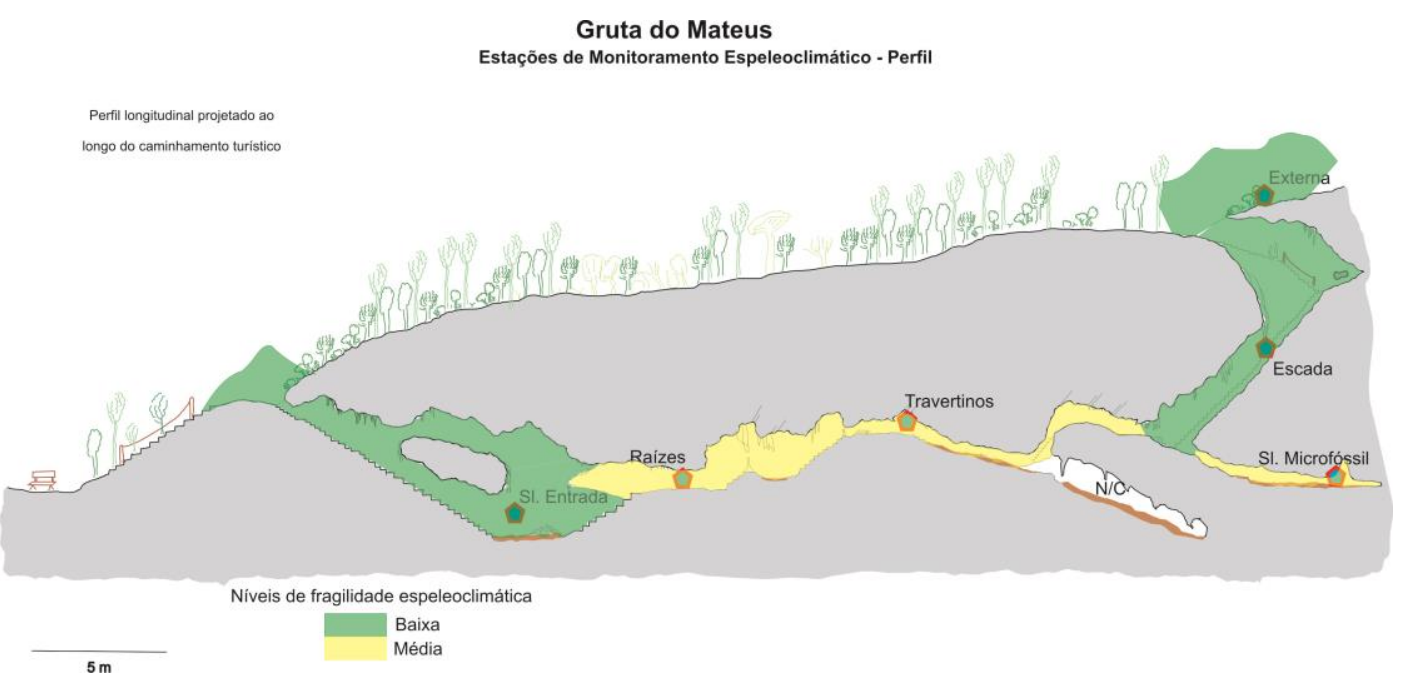

Figura 8. Fragilidade espeleoclimática da gruta do Mateus em perfil.

A gruta do Mateus foi classificada com dois níveis distintos de fragilidade para o espeleoclima. Foram classificadas como áreas de baixa fragilidade aquelas que apresentam maior conectividade com o ambiente externo, o que corresponde às regiões próximas aos acessos da gruta. O restante do trecho classificado recebeu o nível médio, considerando: a) a conectividade relativamente menor com o ambiente externo; e b) a alta capacidade de resiliência atmosférica, evidenciada tanto pelo comportamento da umidade relativa do ar quanto pelo rápido retorno ao estado estacionário da temperatura quando da ocorrência de impactos nos testes-piloto de visitação (Figura 7).

\section{CONCLUSÕES}

O presente estudo ampliou o conhecimento sobre a dinâmica espeleoclimática das cavernas situadas na Serra da Bodoquena, onde estudos desta ordem ainda são escassos. Além disso, os resultados obtidos consistiram em importante contribuição ao Plano de Manejo Espeleológico da gruta do Mateus, especialmente por propiciar a análise das fragilidades microclimáticas da gruta em relação à visitação e possibilitar o cruzamento com as análises de fragilidade de outros estudos ambientais da gruta. Além disso, o estudo apresentou um dos poucos resultados em território nacional sobre dinâmica atmosférica em cavernas com dois acessos, permitindo a aplicação de conceitos clássicos obtidos 
em trabalhos produzidos para realidades ambientais distintas, notadamente, em zonas de clima temperado do globo terrestre.

Considerando a classificação da gruta do Mateus como sendo detentora de níveis baixos e médios de fragilidade espeleoclimática, o presente trabalho demonstrou sua aptidão turística sob a óptica do estudo atmosférico. Os principais fatores que permitiram esta conclusão são a sua elevada dinâmica atmosférica e a baixa intensidade do impacto gerado nos testes-piloto, realizados com grupos de até 23 visitantes. Este número de pessoas é, portanto, sugerido como o máximo de pessoas por grupo que devem adentrar na caverna em caso de futuro uso turístico, já que aglomerações maiores de pessoas podem gerar resultados ora desconhecidos para o ambiente em questão. Desta forma, o presente estudo fornece também subsídios para a obtenção da capacidade de carga turística da gruta do Mateus. O valor sugerido foi compreendido como adequado aos padrões do ambiente desta cavidade, considerado se tratar de um túnel de vento, com distintos acessos, que permite tanto a dissipação maior dos impactos gerados na atmosfera quanto a melhor fluidez da visitação turística.

Recomenda-se como estudo futuro, o monitoramento do período anual completo dos parâmetros atmosféricos estudados neste trabalho, em conjunto com dados de visitação turística (número de grupos por dia, quantidade de pessoas por grupo, intervalo de tempo entre os grupos de visitação), além de registros sobre as concentrações de gás carbônico $\left(\mathrm{CO}_{2}\right)$ - em função de eventuais impactos nos espeleotemas - e dos níveis de Radônio $\left({ }^{222} \mathrm{Rn}\right)$, pensando na segurança de frequentadores habituais, como guias de turismo. Tais estudos permitirão a ampliação do conhecimento espeleoclimático da gruta, bem com a ampliação do conhecimento sobre cavernas em túneis de vento, ainda pouco estudadas no Brasil.

\section{REFERÊNCIAS}

BAILEY, W.G. Microclimatology. In: OLIVER, J.E. (Ed.) Encyclopedia of world climatology.Dordrecht: Springer, 2005. p.486-499.

BOGGIANI, P.C.; SILVA, O.J.; GESICKI, A.L.D.; GALATI, E.; SALLES, L.O.; LIMA, M.M.E.R. Definição de capacidade de carga turística das cavernas do Monumento Natural Gruta do Lago Azul (Bonito, MS). Geociências, Rio Claro, v.26, n.4, p.333348, 2007.

BOURGES, F.; GENTHON, P.; MANGIN, A.; D'HULST, D. Microclimates of I'Aven d'Ornac and other French limestone caves (Chauvet, Esparros, Marsoulas). International Journal of Climatology, v.26, p.1651-1670, 2006.

BUECHER, R.H. Microclimate study of Kartchner caverns, Arizona. Journal of Cave and Karst Studies, Huntsville, v.61, n.2, p.108-120, 1999.

CARDOSO, A. de O.; DIAS, P.L. da S. Identificação de trimestres extremos no regime pluviométrico do Sul e Sudeste do Brasil em relação com anomalias da TSM. Revista Brasileira de Meteorologia, v.19, n.1, p.149-162, 2004. 
CARVALHO, S.M. Microclimatologia subterrânea da gruta Olhos d'Água (Castro, PR). In: DITZEL, C. de H.M.; SAHR, C.L.L. Espaço e cultura: Ponta Grossa e os Campos Gerais. Ponta Grossa: UEPG, 2001. p.443-462.

CIGNA, A.A. Climate of caves. In: GUNN, J. (Ed.) Encyclopedia of caves and karst science. London: Taylor \& Francis, 2004. p.467-475.

DINIZ, G.B.; BERLATO, M.A.; CLARKE, R.T.; FONTANNA, D.C. Identificação de regiões homogêneas de temperatura máxima e mínima do Rio Grande do Sul. Revista Brasileira de Agrometeorologia, v.11, n.2, p.303-312, 2003.

ERASO, A. La corrosión climática em las cavernas. Boletín Geológico y Minero, v.80, n.6, p.564-581, 1969.

FREITAS, C.R. de; SCHMEKAL, A. Studies of condensation/evaporation processes in the Glowworm cave, New Zealand. International Journal of Speleology, Bologna, v.35, n.2, p.75-81, 2006.

FRITZSONS, E.; MANTOVANI, L.E.; AGUIAR, A.V. de. Relação entre altitude e temperatura: uma contribuição ao zoneamento climático no Estado do Paraná. Revista de Estudos Ambientais, Blumenau, v.10, n.1, p.49-64, 2008.

FUNDAÇÃO FLORESTAL - FUNDAÇÃO PARA A CONSERVAÇÃO FLORESTAL DO ESTADO DE SÃO PAULO/SECRETARIA DO MEIO AMBIENTE; INSTITUTO EKOS BRASIL (Coords.) Plano de manejo espeleológico do Parque Estadual Turístico do Alto Ribeira. São Paulo: Fundação Florestal, 2010. 765 p.

GERARDI, L.H. de O.; SILVA, B.C.N. Quantificação em geografia.São Paulo: Difel, 1981. $161 \mathrm{p}$.

GESB - Grupo de Espeleologia da Serra da Bodoquena. Mapa da gruta do Mateus.Escala 1:1000. Dourados: GESB, 2012.

HEATON, T. Caves: a tremendous range in energy environments on earth. National Speleological Society News, Huntsville, v.08, n.44, p.301-304, 1986.

LANDIM, P.M.B. Análise estatística de dados geológicos. 2.ed. Rio Claro: Edunesp, 2003. 253 p.

LOBO, H.A.S. Monitoring of water temperature of the Roncador river: contribution to speleoclimate analysis and tourist management of the cave of Santana (Iporanga, Brazil). Tourism and Karst Areas, v.4, n.1, p.33-44, 2011.

LOBO, H.A.S. Espeleoclima e suas aplicações no manejo do turismo em cavernas. Revista do Depto. de Geografia - USP, v.23, p.27-54, 2012.

LOBO, H.A.S. circulação microclimática entre superfície, grandes dolinas e cavernas no carste de São Desidério, Bahia. Sociedade e Natureza, v.25, n.1, p.163-178, 2013.

LOBO, H.A.S.; MORETTI, E.C.Tourism in caves and the conservation of the speleological heritage: the case of Serra da Bodoquena (Mato Grosso do Sul State, Brazil). Acta Carsologica, v.38, p.265-276, 2009. 
LOBO, H.A.S.; PERINOTTO, J.A. de J.; POUDOU, S. Análise de agrupamentos aplicada à variabilidade térmica da atmosfera subterrânea: contribuição ao zoneamento ambiental microclimático de cavernas. Revista de Estudos Ambientais, Blumenau, v.11, n.1, p.22-35, 2009.

LOBO, H.A.S.; PERINOTTO, J.A.J.; BOGGIANI, P.C. non-linear response of cave temperature subjected to tourist visitation (cave of Santana, PETAR - Brazil): implications for carrying capacity of show caves.In: INTERNATIONAL CONGRESS ON SCIENTIFIC RESEARCH IN SHOW CAVES, 2012, Divaca. International Congress on Scientific Research in Show Caves. Postojna: Institut za raziskovanje krasa ZRC SAZU, 2012, p.35-36.

LOBO, H. A. S.; TRAJANO, E.; MARINHO, M. A.; BICHUETTE, M.E.; SCALEANTE, J. A. B.; SCALEANTE, O.A.F.; ROCHA, B.N.; LATERZA, F.V. Projection of Tourist Scenarios onto Fragility Maps: Framework for Determination of Provisional Tourist Carrying Capacity in a Brazilian Show Cave. Tourism Management, v.35, p.234-243, 2013.

LOURENÇÃO, M.L.F.; LOBO, H.A.S.; CORDEIRO-BORGHEZAN, L.M. (Coords.). Plano de manejo espeleológico da gruta do Mateus.Bonito: GESB, 2013. 194 p.

LUETSCHER, M.; LISMONDE, B.; JEANNIN, P.Y. Heat exchanges in the heterothermic zone of a karst system: Monlesi cave, Swiss Jura mountains. Journal of Geophysical Research, v.113, p.1-13, 2008.

PULIDO-BOSCH, A.; MARTÍN-ROSALES, W.; LÓPEZ-CHICANO, M.; RODRÍGUEZNAVARRO, M.; VALLEJOS, A. Human impact in a tourist karstic cave (Aracena, Spain). Environmental Geology, Berlin, v.31 n.3/4, p.142-149, 1997.

ROCHA, B.N.; GALVANI, E. Microclima de ambientes cavernícolas: estudo de caso da gruta da Santa, Parque Estadual de Intervales, SP. Revista Brasileira de Climatologia, v.9, p.21-34, 2011.

SÁNCHEZ-MORAL, S.; SOLER, V.; CAÑAVERAS, J.C.; SANZ-RUBIO, E.; VAN GRIEKEN, R.; GYSELS, K. Inorganic deterioration affecting Altamira cave, N Spain: quantitative approach to wall-corrosion (solutional etching) processes induced by visitors. The Science of the Total Environment, v.243/244, p.67-84, 1999.

STOEVA, P.; STOEV, A. Cave air temperature response to climate and solar and geomagnetic activity. Memorie Della Societá Astronomica Italiana, v.76, p.1042-1047, 2005.

VERÍSSIMO, C.U.V.; RICARDO, J.M.; BARCELOS, A.C.; NOGUEIRA NETO, J.A.; SILVA FILHO, W.F.; NACIMENTO JÚNIOR, J.V.; PAIVA, A.O. Espeleoturismo e microclima da gruta de Ubajara, CE.Estudos Geológicos,Recife, v.15, p.244-253, 2005. 